\title{
Layer charge and heavy metals structures in hydrated 2:1 silicates: state of the art and new advances on cadmium
}

\author{
Daniele Malferrari ${ }^{\mathrm{I}}$, Maria Franca Brigatti ${ }^{*}, \mathrm{I}$, Chiara Elmi ${ }^{\mathrm{I}}$, Angela Laurora ${ }^{\mathrm{I}}$ and Giovanni Valdrè ${ }^{\mathrm{II}}$ \\ I Dipartimento di Scienze della Terra, Università di Modena e Reggio Emilia, L.go S. Eufemia 19, 41100 Modena, Italy \\ II Dipartimento di Scienze della Terra e Geologico-Ambientali, Università di Bologna, Piazza di Porta San Donato, 40126 Bologna, Italy
}

Received October 17, 2008; accepted January 14, 2009

\section{Montmorillonite / Vermiculite / Layer charge / Heavy metals / Cadmium / \\ Powder diffraction structure analysis / X-ray diffraction}

\begin{abstract}
This study will discuss how layer charge can affect chemical speciation and topology of heavy metals adsorbed to 2:1 layer silicates, by providing: i) an overview of literature data; ii) experimental data on $\mathrm{Cd}$ complexes adsorbed by $2: 1$ layer silicates with different layer charge (montmorillonite and vermiculite); iii) a comparison between our results and literature data. This study will also be supported by several different experimental techniques such as chemical and thermal analyses, X-ray powder diffraction and X-ray absorption spectroscopy.

Based on our data $\mathrm{Cd}$ atoms were found to complex water molecules in both clay minerals and to show fourfold coordination in montmorillonite $(\mathrm{Cd}-\mathrm{O}$ distances of $2.24 \AA)$ and six-fold coordination in vermiculite $(\mathrm{Cd}-\mathrm{O}$ distances of 2.16 and $2.28 \AA$ ). Furthermore our models clearly suggest that $\mathrm{Cd}$ mainly bonds to interlayer water, without neglecting the more limited, but still significant, $\mathrm{Cd}$ multinuclear surface complexes at the octahedral broken edges. Both clay minerals show $\mathrm{H}_{2} \mathrm{O} / \mathrm{Cd}$ ratio, as evidenced by thermal analyses, drastically higher than expected from X-ray absorption spectroscopy data, thus implying that most of the water molecules are only loosely coordinated to interlayer cations.
\end{abstract}

\section{Introduction}

Layer silicates $2: 1$, such as clay minerals, are widely used also because of their surface properties, which significantly affect the interaction of the layer with waste materials, including heavy metals, organic molecules, and organo-metallic complexes. Surface properties are significantly influenced by layer charge. In swelling 2:1 clays, such as montmorillonite- and vermiculite-like structure, the $2: 1$ layers are constituted by two tetrahedral sheets sandwiching an octahedral one, thus finally imparting a negative charge to the layer, which is, by definition, the layer charge [1]. The overall structure neutrality is assured by

* Correspondence author (e-mail: e-mail: brigatti@unimore.it) interlayer cations, which are placed between two adjacent 2:1 layers (i.e., in the interlayer region) and are surrounded by water molecules. Layer silicates can present different values and location of layer charge, which can be generated by tetrahedral or octahedral substitutions. In montmorillonite-like layers, the negative layer charge, resulting from $\mathrm{R}^{2+}$-for- $\mathrm{R}^{3+}$ substitutions in the octahedral sheet, is distributed among basal oxygen atoms that are thus weakly under-saturated. Otherwise, when $\mathrm{Al}^{3+}$-for$\mathrm{Si}^{4+}$ substitution occurs in tetrahedral sheet, such as in vermiculite, the charge deficit is distributed among the nearest three neighbour basal oxygen atoms. These oxygen atoms are strongly under-saturated, thus giving strong attractive interactions with interlayer cations, which may result in a lower layer hydration [2,3]. A further effect is on adsorption processes. According to the HSAB theory of Pearson $[4,5]$, the hydrated interlayer cations and the layer of smectites can be considered Lewis acids and bases, respectively [6]. The location of the layer charge determines the strength of the Lewis base: the 2:1 layer behaves like a soft base when the layer charge is located in the octahedral sheet, whereas it behaves like a hard base when the charge is located in the tetrahedral sites. Hard bases bond preferentially to hard acids and soft bases to soft acids, thus also confirming the fundamental role of layer charge location on exchange processes, since different heavy metal cations can be classified as hard or soft Lewis acids. Furthermore heavy metals do not only form complexes with water molecules in the interlayer (Clike structures, Fig. 1), but also occur in different sorption sites into clay structure, depending from layer charge. These latter structures, as detailed in Fig. 1, can be classified as multinuclear complexes (A- and B-like structures) and as inner-sphere complexes (D-like structures) [7, 8]. Formation of inner sphere complexes occurs when ions bind directly to the surface without involving any water molecule. It is limited to ions, like heavy metals cations, with high affinity for surface sites, also showing covalent bonds. This is, according to recent studies, the case for $\mathrm{Cu}$ in vermiculite, which is hosted mainly at vermiculite edges, rather than in the interlayer, without forming any multinuclear surface precipitates. In particular, the presence of a second-shell for $\mathrm{Al}, \mathrm{Si}$, or $\mathrm{Mg}$ atoms at $3.02 \AA$ and the angle between $\mathrm{Cu}$ atom and the mineral sorption 


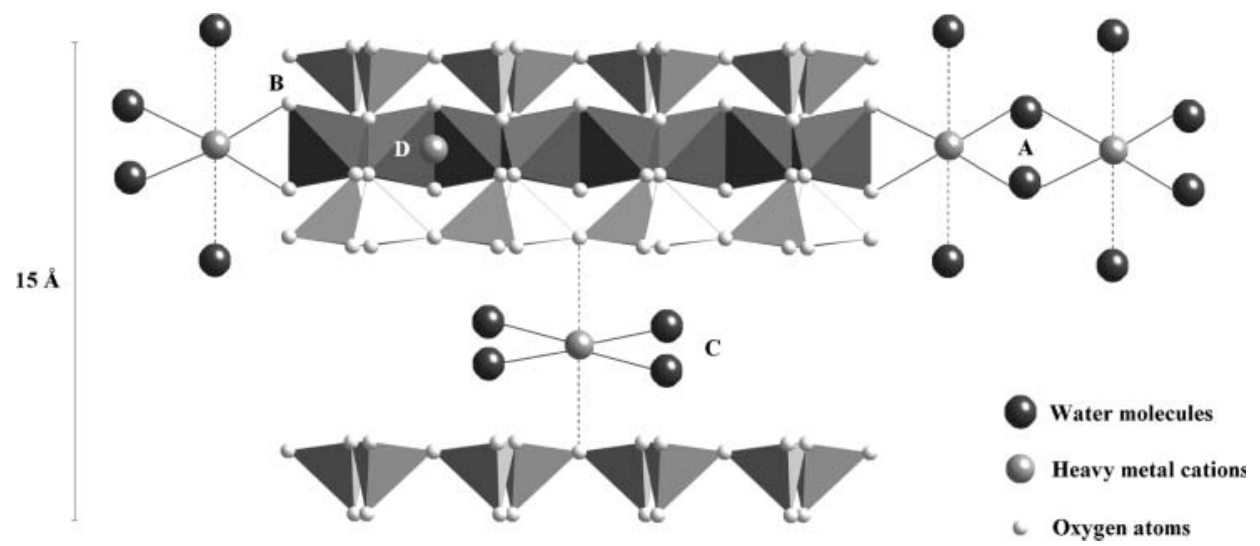

Fig. 1. Sketch of a 2:1 layer silicate with cations forming both multinuclear complexes such as dimers (A), monomer (B) or adsorbed in the interlayer (C, here in four-fold coordination) and inner-sphere complexes (D) bonded to octahedral broken edges. sites (i.e. $68^{\circ}$ with respect to [001]) suggest that the bonding environment of $\mathrm{Cu}$ in vermiculite edge is corner-sharing, rather than edge sharing, with tetrahedral $\mathrm{Si}$ and $\mathrm{Al}$, or with $\mathrm{Mg}$ ligands in the octahedron [9]. Finally, at high temperatures, some heavy metal cations can also enter vacant sites in the octahedral sheet $[10,11]$.

In montmorillonite and in beidellite (a dioctahedral smectite with layer charge mostly located in the tetrahedral sites but with a net negative tetrahedral charge lower than in vermiculite) EXAFS data suggest that $\mathrm{Cu}$ is surrounded by four oxygen atoms at $\mathrm{Cu}-\mathrm{O}$ distances less than $2.0 \AA$. The $\mathrm{Cu}-\mathrm{Cu}$ distances of two neighbouring $\mathrm{Cu}$ atoms are 3.0 and $6.0 \AA$, approximately. The first distance agrees with the formation both of inner sphere complexes and multinuclear surface complexes on the mineral edge sites, whereas the latter agrees with hydrated $\mathrm{Cu}$ cations in the interlayer [12, 13]. Furthermore, when temperature increases up to $350^{\circ} \mathrm{C}$, a proportion of $\mathrm{Cu}$ (II) cations diffuses into the octahedral vacancies, which further increase when increasing the heating time [10, 14].

Studies on mercury hosted in $2: 1$ silicate layers [15, 16] show that the metal binds to the $2: 1$ layer as interlayer $\mathrm{Hg}-\mathrm{OH}_{2}$ complexes (C-like structure) both in montmorillonite and vermiculite and forms A- and B-like structures at the edge sites only in vermiculite (Fig. 1). In fact, the most relevant contribution to the EXAFS region of montmorillonite can be ascribed to $\mathrm{Hg}$ surrounded by six oxygen atoms, three closer to $\mathrm{Hg}$, at a distance of $1.99 \AA$ and the remaining at $2.40 \AA$. Like in montmorillonite, $\mathrm{Hg}$ in vermiculite is surrounded by six oxygen atoms with two triads of atoms at 1.95 and $2.32 \AA$ from the central $\mathrm{Hg}$, respectively. Furthermore, longer $\mathrm{Hg}-\mathrm{O}$ distances at 2.77 and $2.93 \AA$ and $\mathrm{Hg}-\mathrm{Hg}$ distances at 3.31 and $3.37 \AA$ confirm the presence of inner sphere and multinuclear surface complexes bonded to the corners of vermiculite broken edges [15]. Thermal behaviour of the two $\mathrm{Hg}-$ treated 2:1 layer silicates is different, mostly because of the different layer charge [16]. In montmorillonite $\mathrm{Hg}$ ascribed to $\mathrm{Hg}-\mathrm{H}_{2} \mathrm{O}$ interlayer complexes is removed at temperature below $250{ }^{\circ} \mathrm{C}$, without affecting $\mathrm{HgO}$ innersphere and multinuclear complexes, at least up to $T=450{ }^{\circ} \mathrm{C}$. Afterwards, XANES spectra show that the $\mathrm{Hg}_{-} \mathrm{L}_{\text {III }}$ edge signal gradually decreases and completely disappears at $T=700{ }^{\circ} \mathrm{C}$, indicating that the layer is completely $\mathrm{Hg}$ free. The thermal behaviour of $\mathrm{Hg}$ treated vermiculite suggests the prevalence of $\mathrm{HgO}$ inner-sphere and multinuclear complexes. Both reactions associated to $\mathrm{Hg}$ release occur in conjunction with dehydroxilation reactions at $T \cong 500{ }^{\circ} \mathrm{C}$ and at $T \cong 800{ }^{\circ} \mathrm{C}$. This behaviour is probably not associated to $\mathrm{Hg}$ occupying the octahedral sites, but rather to crystal chemical features of this layer silicate. Mercury oxide, if hosted in the ditrigonal cavity, can strongly bind the silicate layer; the dehydroxilation reaction of the octahedral sheet could, in this way, catalyze the thermal decomposition of the adsorbed $\mathrm{Hg}$.

Clays and related layered minerals are usually fine grained and poorly crystalline materials, lacking longrange order, especially for what concerns the stacking behaviour of the layers. The structure characterization of the crystallographic surrounding of sorbed species is thus mostly based on powder data. This study will include Xray powder diffraction, thermal analysis and X-ray absorption spectroscopy results, to demonstrate the relevance of layer charge location in controlling the topology of $\mathrm{Cd}$ complexes. The structural environment of $\mathrm{Cd}$ in the soft base montmorillonite and in the hard base vermiculite will be thus investigated and results compared to previously referenced literature data.

\section{Experimental}

\section{Samples and treatments}

Samples used here are montmorillonite and vermiculite. The soft base montmorillonite is the Clay Minerals Society standard STx-1 from Gonzales County (Texas), chemical formula ${ }^{[\mathrm{iv}]} \mathrm{Si}_{4.0}{ }^{[\mathrm{vi}]}\left(\mathrm{Al}_{1.59} \mathrm{Fe}^{3+}{ }_{0.035} \mathrm{Fe}^{2+}{ }_{0.01} \mathrm{Mg}^{2+}{ }_{0.14} \mathrm{Ti}_{0.01}\right)$ ${ }^{\text {[xii] }}\left(\mathrm{Ca}_{0.12} \mathrm{Na}_{0.035} \mathrm{~K}_{0.005}\right) \mathrm{O}_{10}(\mathrm{OH})_{22}$ and cation exchange capacity $(\mathrm{CEC})=84.4 \mathrm{meq} / 100 \mathrm{~g}$. The hard base vermiculite is from Bikita (Zimbabwe), with chemical formula ${ }^{[\mathrm{iv}]}\left(\mathrm{Si}_{3.041} \mathrm{Al}_{0.959}\right)^{[\mathrm{vi}]}\left(\mathrm{Ti}_{0.023} \mathrm{Al}_{0.049} \mathrm{Fe}^{3+}{ }_{0.403} \mathrm{Mg}_{2.518} \mathrm{Mn}_{0.007}\right)$ ${ }^{\text {[xii] }}\left(\mathrm{Mg}_{0.228} \mathrm{Na}_{0.005}\right) \mathrm{O}_{10}\left(\mathrm{~F}_{0.152} \mathrm{OH}_{1.848}\right)$ and $\mathrm{CEC}=116 \mathrm{meq} /$ $100 \mathrm{~g}$. Additional mineralogical data on studied samples are reported in $[17,18]$.

The procedure used to obtain Cd-complexed minerals is discussed in detail in Ref. [18] and here briefly summarised. The size fraction $<1 \mu \mathrm{m}$ of each sample is saturated with $1 \mathrm{M}$ solution of sodium acetate. $\mathrm{Cd}$ complexed minerals are then obtained by dipping and continuously shaking each sample in $10^{-3} \mathrm{M} \mathrm{Cd}$ solution at $\mathrm{pH}=6.5$ and $T=25^{\circ} \mathrm{C}$. Chosen solution concentration and $\mathrm{pH}$ 
value are consistent with theoretical calculations performed via the MINTEQA2 program [19]. As described in [18], several washing steps are applied to samples after each treatment.

\section{X-ray powder diffraction (XRPD)}

XRPD patterns were recorded from oriented mounts of the air-dried samples in the temperature range $25 \leq T\left({ }^{\circ} \mathrm{C}\right) \leq 400$ (heating rate $2{ }^{\circ} \mathrm{C} / \mathrm{min}$ ) using a Philips $X^{\prime}$ Pert PRO diffractometer equipped with X'Celerator detector $(\mathrm{CuK} \alpha$ radiation $40 \mathrm{kV}$ and $40 \mathrm{~mA}$; two theta range: 4-75 ; quartz as standard) and HTK16 Anton Paar in situ heating apparatus.

\section{Thermal analysis (TGA)}

Thermo-gravimetric behaviour is investigated by a Seiko SSC 5200 thermal analyzer. The instrument is coupled with a quadrupole mass spectrometer (ESS, GeneSys Quadstar 422) to analyze gases evolved during thermal reactions.

\section{X-ray absorption spectroscopy (XAS)}

Cd $K$-edge X-ray absorption spectra are collected at the European Synchrotron Radiation Facility (ESRF), GILDA beam-line, in transmission mode on powder-pressed disks constituted from an appropriate mixture of sample (clay mineral) and cellulose. Energy calibration is performed using a Cd metal foil with the first inflection point of the $K$-absorption edge at $26711 \mathrm{eV}$. Samples are analyzed at liquid nitrogen temperature using an evacuated cryostat.

The experimental Fourier filtered EXAFS spectrum is compared to theoretical EXAFS spectra, calculated via FEFF-8 program [20] using $\mathrm{Cd}(\mathrm{OH})_{2}$ and $\mathrm{CdO}$ as reference compounds. A Fourier transform of the experimental spectrum provides the approximate radial distribution function around the central absorbing atom; the peaks represent shells of atoms surrounding the central one.

\section{Results}

After treatment, according to the different CEC values and despite the greater amount of $\mathrm{H}_{2} \mathrm{O}$ in montmorillonite, the $\mathrm{Cd}$ content is with $9.47 \mathrm{meq} / 100 \mathrm{~g}$ lower than in vermiculite $(10.90 \mathrm{meq} / 100 \mathrm{~g})$ (Fig. 2a). The weight loss related to $\mathrm{H}_{2} \mathrm{O}$ molecules in the temperature range $25-250{ }^{\circ} \mathrm{C}$ is $12.4 \%$ for montmorillonite and $9.4 \%$ for vermiculite. Similarly, $d_{001}$ values at room temperature are 15.42 and $14.80 \AA$ for montmorillonite and vermiculite, respectively (Table 1). The variation of these distances, as a function of temperature, can be ascribed to the different value and location of layer charge. The position of the (001) reflection decreases continuously in the temperature range $25 \leq T\left({ }^{\circ} \mathrm{C}\right) \leq 300$, suggesting that the closest $2: 1$ packing configuration is reached at $275^{\circ} \mathrm{C}$ for soft base montmorillonite $\left(d_{001}=9.90 \AA\right)$, unlike the hard base vermiculite that maintains a greater periodicity $\left(d_{001}=10.30 \AA\right)$ up to $300{ }^{\circ} \mathrm{C}$. Montmorillonite, despite its higher $\mathrm{H}_{2} \mathrm{O}$


Fig. 2. Thermal analyses of $\mathrm{Cd}$ treated montmorillonte and vermiculite. (a) Distribution of the weight loss in various thermal ranges as a function of the main reaction occurring during heating and calculation of the deconvoluted curves for montmorillonite (b) and vermiculite (c).

content, thus requires a lower energy to reach its closest packing configuration, because of the lower bond strength of basal tetrahedral oxygen atoms toward interlayer species. This result is finally consistent with a more disordered $\mathrm{H}_{2} \mathrm{O}$-rich configuration for montmorillonite, where $\mathrm{H}_{2} \mathrm{O}$ molecules are weakly bonded to the layer structure.

The different water to heavy metal ratio may also suggest either that the interlayer cation $(\mathrm{Cd})$ is less hydrated 
Table 1. Variation of $d_{001}(\AA)$ spacing as function of temperature.

\begin{tabular}{lll}
\hline Temp. $\left({ }^{\circ} \mathrm{C}\right)$ & Cd(II)-mont. & Cd(II)-verm. \\
\hline 25.0 & 15.42 & 14.80 \\
50.0 & 12.78 & 12.00 \\
75.0 & 11.94 & 11.90 \\
100 & 11.75 & 11.80 \\
125 & 11.28 & 11.70 \\
150 & 10.44 & 11.00 \\
175 & 10.15 & 10.50 \\
200 & 10.07 & 10.40 \\
225 & 9.95 & 10.40 \\
250 & 9.91 & 10.40 \\
275 & 9.90 & 10.30 \\
300 & 9.90 & 10.30 \\
\hline
\end{tabular}

in vermiculite than in montmorillonite or the presence, in this latter, of a greater number of water molecules, not bonded to the cation, also according to what reported in [21].

Further information, on the role of the interlayer cation, may be derived from the dehydration dynamics at increasing temperature, since different bond energy and layer topology correspond to different values of reaction temperature. It should however be considered that the hydration heterogeneity may render extremely difficult the characterization of dehydration dynamics.

Reported $d_{001}$ values at room temperature are consistent for both minerals with bihydrated interlayer structures. When increasing temperature, the shape of the peaks (not reported) and $d_{001}$ values (Table 1 ) suggest that the structures gradually evolve from one hydration state to another, probably via the formation of mixed-layer structures, as also observed for untreated montmorillonite [21]. Dehydration reactions show two main effects for both the clay minerals in $25 \leq T\left({ }^{\circ} \mathrm{C}\right) \leq 250$ range (Fig. $2 \mathrm{~b}$ and $2 \mathrm{c}$ ), probably contributed by various reactions as suggested by deconvoluted curves. The best fit for the first effect (at $T$ $\cong 75^{\circ} \mathrm{C}$ in montmorillonite and $T \cong 115^{\circ} \mathrm{C}$ in vermiculite) is obtained with the contribution of three Gaussian fitting curves. The temperature values given by the maximum point of the second and third Gaussian curve could represent the transition from two hydrated layer to one hydrated layer structure and from one hydrated layer to dehydrated layer structure, respectively. The maximum of the first Gaussian curve ( $T=45$ and $75^{\circ} \mathrm{C}$ in montmorillonite and vermiculite, respectively) and the second effect, revealed at temperatures lower than $250{ }^{\circ} \mathrm{C}$, well evidence that the water to $\mathrm{Cd}$ ratio in both clay minerals is drastically higher (35.2 and 23.8 in montmorillonite and vermiculite, respectively) than suggested by X-ray Absorption Spectroscopy (four-fold coordination for montmorillonite and six-fold coordination for vermiculite), thus probably indicating that in both layer silicates most of the water molecules are not coordinated, or only weakly coordinated, to the interlayer cation. The removal of these water molecules strongly depends on their location and could take part both at very low temperature (surface water, first Gaussian curve fitting the first effect) or at higher tem- perature (micro- and/or macro-pore water, effects at 155 and $210{ }^{\circ} \mathrm{C}$ for montmorillonite and vermiculite, respectively).

The higher reaction temperature observed in vermiculite with respect to montmorillonite well agrees with the higher layer charge of the hard base. Besides, the higher $\mathrm{Cd}$ content in vermiculite can additionally explain the different dehydration kinetics of the two clay minerals: in vermiculite, the $\mathrm{Cd}$ attraction toward water molecules in interlayer is greater than in montmorillonite, thus allowing a better organization of the interlayer complexes.

The experimental EXAFS spectrum $(\chi k)$ of montmorillonite shows four main coordination shells at 2.24, 2.98, 3.30 and $4.76 \AA$ (Fig. 3). The comparison with $\mathrm{Cd}(\mathrm{OH})_{2}$ model compound suggests that distances at $2.24 \AA$ (fourfold coordination) are consistent with $\mathrm{Cd}-\mathrm{O}$ bond in $\mathrm{Cd}-\mathrm{OH}_{2}$ complexes (i.e., C-like structures, Fig. 1). A single $\mathrm{Cd}-\mathrm{Cd}$ distances at $3.30 \AA$ and two-fold coordinated $\mathrm{Cd}-\mathrm{Cd}$ at $4.76 \AA$ are also present. The first distance is consistent with the formation of multinuclear surface complexes (A-like structures, Fig. 1), the second distance suggests $\mathrm{Cd}-\mathrm{OH}_{2}$ complexes in the interlayer. The shell at $2.98 \AA$ could be attributed to bonds between A- or B-like structures with tetrahedral or octahedral broken-edge corners (i.e., $\mathrm{Cd}-{ }^{[\mathrm{VI}]} \mathrm{Al}$ or $\mathrm{Cd}-{ }^{[\mathrm{IV}]}(\mathrm{Si}, \mathrm{Al})$ bonds). To clarify previous assumptions a structural model was simulated starting from pyrophyllite atomic positions. Main differences between montmorillonite and pyrophyllite are related to layer thickness, which can be measured for both minerals. Pyrophyllite structural coordinates [22] in $P 1$ symmetry, were thus converted and suited to montmorillonite unit cell. Different scenarios, either with Cd located only at the interlayer or also bonded to oxygen atoms lo-

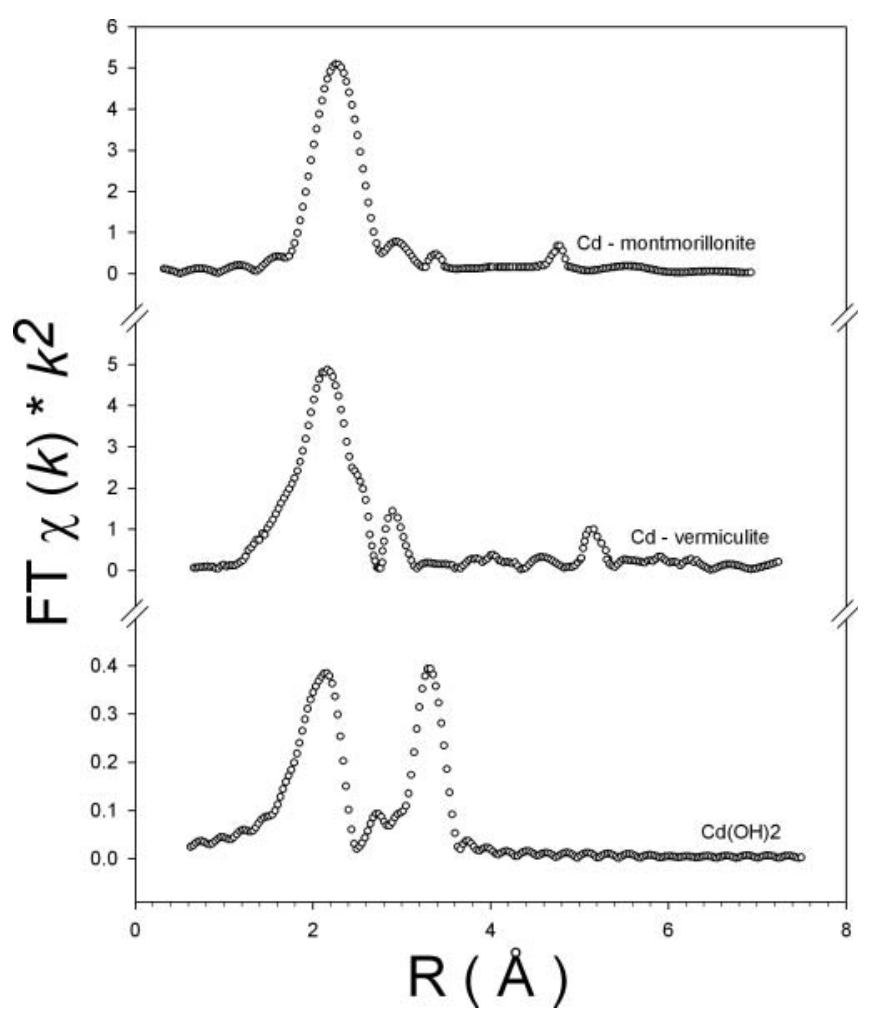

Fig. 3. Fourier Transform of Cd $K$-edge EXAFS experimental data for Cd-exchanged montmorillonite and vermiculite and for $\mathrm{Cd}(\mathrm{OH})_{2}$. 
cated at the octahedron and/or at the tetrahedron broken edges, were thus formulated. The model clearly suggests that $\mathrm{Cd}$ mainly bonds to interlayer water and that multinuclear surface complexes bond to octahedral broken edges.

As in montmorillonite, vermiculite experimental spectra are well fitted by $\mathrm{Cd}(\mathrm{OH})_{2}$ model compound. In vermiculite, $\mathrm{Cd}$ is coordinated to six water molecules, four with $\mathrm{Cd}-\mathrm{O}$ distances at $2.16 \AA$ and two with $\mathrm{Cd}-\mathrm{O}$ distances at $2.28 \AA$. The structural model obtained from parameters reported in [23], suggests that the formation of inner sphere complexes (D-like structure, Fig. 1) and multinuclear surface complexes at the octahedral edges (A-, B-like structure, Fig. 1) cannot be excluded. In fact, the $\mathrm{Cd}-\mathrm{Cd}$ distances of $2.90 \AA$ indicate that $\mathrm{Cd}$ is adsorbed as a multinuclear surface complex. The shell at $5.05 \AA$ is representative of $\mathrm{Cd}$ adsorbed in the interlayer. Thus, the interlayer cations appear to be more separated in vermiculite than in montmorillonite, also consistently with its six-fold coordination with water molecules.

\section{Concluding remarks}

This contribution addresses the structural surrounding and coordination of $\mathrm{Cd}$ in both high and low charge layer silicates. A comparison with literature data is also introduced for $\mathrm{Cu}$ and $\mathrm{Hg}$.

All considered heavy metals are demonstrated either to form multinuclear surface complexes at the layer broken edges or to complex interlayer $\mathrm{H}_{2} \mathrm{O}$. However, different structures can be identified depending on layer silicate charge and on the complexing heavy metal. Layer charge location mostly affects the interlayer hydration: in montmorillonite showing low layer charge, water molecules, also not bonded to the interlayer cation, are present in greater amount. $\mathrm{Cd}$ and $\mathrm{Hg}$ show a distorted six-fold coordination with two longer distances and four shorter ones, where bond lengths depend on layer charge. $\mathrm{Cu}$ is an exception because of its predominant four-fold coordination in montmorillonite and does not form interlayer complexes in vermiculite but rather multinuclear complexes at layer broken edges, unlike $\mathrm{Cd}$ and $\mathrm{Hg}$, which give both interlayer and multinuclear complexes at layer broken edges. This different behaviour can be possibly ascribed to the heavy metal ionic radius, which is shorter in $\mathrm{Cu}$.

Acknowledgments. Comments from two anonymous reviewers are kindly acknowledged. We would like to acknowledge the financial support from PRIN "Micas: cation ordering, anionic composition as petrogenetic control factors" and the beam-time availability at ESRF (European Synchrotron Radiation Facility, BM08 - Gilda Beam Line). An appreciated support was also provided by Centro Interdipartimentale Grandi Strumenti (CIGS) of Modena and Reggio Emilia University and by its staff.

\section{References}

[1] Brindley, G.W.; Brown, G.; Crystal Structures of Clay Minerals and their X-ray identification. Mineralogical Society, London 1980 .
[2] Laird, D.A.: Model for crystalline swelling of 2:1 phyllosilicates. Clays Clay Miner. 44 (1996) 553-559.

[3] Laird, D.A.: Layer charge influences on the hydration of expandable $2: 1$ phyllosilicates. Clays Clay Miner. 47 (1999) 630636.

[4] Pearson, R.G.: Hard and soft acids and bases. J. Am. Chem. Soc. 85 (1963) 3533-3539.

[5] Pearson, R.G.: Hard and soft acids and bases HSAB, part 1: Fundamental principles. J. Chem. Educ. 45 (1968) 581-587.

[6] Xu, S.; Harsh, J.B.: Alkali cation selectivity and surface charge of $2: 1$ clay minerals. Clays Clay Miner. 40 (1992) 567-574.

[7] Cheah, S.F.; Brown, G.E.; Parks, G.A.: XAFS study of $\mathrm{Cu}$ model compounds and $\mathrm{Cu}$ sorption products on amorphous $\mathrm{SiO}_{2}$, $\mathrm{Al}_{2} \mathrm{O}_{3}$ and anatase. Am. Mineral. 55 (2000) 118-132.

[8] Strawn, D.G.; Palmer, N.P.; Furnare, L.; Goodell, C.; Amonette, J.; Ukkadapu, R.: Mechanisms of copper sorption on smectites. Clays Clay Miner. 52 (2004) 321-333.

[9] Furnare, L.J.; Vailionis, A.; Strawn, D.G.: Polarized XANES and EXAFS spectroscopic investigation into copper(II) complexes on vermiculite. Geochim. Cosmochim. Ac. 69 (2005) 5219-5231.

[10] McBride, M.; Mortland, M.: Copper (II) interactions with montmorillonite: Evidence from physical methods. Proc. Soil Sci. Soc. Am. 38 (1974) 408-415.

[11] Mosser, C.; Michot, L.J.; Villeras, F.; Romeo, M.: Migration of cations in copper(II)-exchanged montmorillonite and laponite upon heating. Clays Clay Miner. 45 (1997) 789-802.

[12] Morton, J.D.; Semrau, J.D.; Hayes, K.F.: An X-ray absorption spectroscopy study of the structure and reversibility of copper adsorbed to montmorillonite clay. Geochim. Cosmochim. Ac. 65 (2001) 2709-2722.

[13] Brigatti, M.F.; Colonna, S.; Malferrari, D.; Medici, L.: Characterization of $\mathrm{Cu}$-complexes in smectite with different layer charge location: chemical, thermal and EXAFS studies. Geochim. Cosmochim. Ac. 68 (2004) 781-788.

[14] Karmous, M.S.; Ben Rhaiem, H.; Naamen, S.; Oueslati, W.; Ben Haj Amara A.: The interlayer structure and thermal behavior of $\mathrm{Cu}$ and $\mathrm{Ni}$ montmorillonites. Z. Kristallogr. Suppl. 23 (2006) 431-436.

[15] Brigatti, M.F.; Colonna, S.; Malferrari, D.; Medici, L.; Poppi, L.: Mercury adsorption by montmorillonite and vermiculite: a combined XRD, TG-MS, and EXAFS study. Appl. Clay Sci. 28 (2005) 1-8.

[16] Malferrari, D.; Brigatti, M.F.; Marcelli, A.; Chu, W.; Wu, Z.: Modification of $\mathrm{Hg}$ complexes in layered silicates with temperature: an in situ XAS study. Micropor. Mesopor. Mat. 107 (2008) 128-133.

[17] Costanzo, P.M.; Guggenheim, S.: Clay Minerals Society Source. Clays Clay Miner. 49 (2001) 371-453.

[18] Malferrari, D.; Brigatti, M.F.; Laurora, A.; Pini, S.; Medici, L.: Sorption kinetics and chemical forms of $\mathrm{Cd}(\mathrm{II})$ sorbed by thiolfunctionalized 2:1 clay minerals. J. Hazard. Mater. 143 (2007) $73-81$.

[19] Allison, J.D.; Brown, D.S.; Novo-Gradac, K.J.: MINTEQA2/ PRODEFA2, A geochemical assessment model for environmental system: version 3.0, 1991. United States Environmental Protection Agency, Athens, Georgia 30613.

[20] Ankudinov, A.L.; Ravel, B.; Rehr, J.J.; Conradson, S.D.: Real space multiple scattering calculation and interpretation of X-ray Absorption Near Edge Structure. Phys. Rev. B 58 (1998) 75657574.

[21] Ferrage, E.; Lanson, B.; Sakharov, B.A.; Geoffroy, N.; Jacquot, E.; Drits, V.A.: Investigation of dioctahedral smectite hydration properties by modeling of X-ray diffraction profiles: influence of layer charge and charge location. Am. Mineral. 92 (2007) $1731-1743$.

[22] Lee, H.-L.; Guggenheim, S.: Single crystal refinement of pyrophyllite-1Tc. Am. Mineral. 66 (1981) 350-357.

[23] Shirozu, H., Bailey, S.W.: Crystal structure of a two-layer Mgvermiculite. Am. Mineral. 51 (1966) 1124-1143. 